\title{
Why Don't You Do Something to Help Me? Digital Humanism: A Call for Cities to Act
}

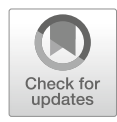

\author{
Michael Stampfer
}

\begin{abstract}
Cities across the globe face the challenge of managing massive digitization processes to meet climate goals and turn urban agglomerations into more livable places. Digital Humanism helps us to see and define how such transformations can be done through empowerment of citizens and administrations, with a strong political agenda calling for inclusion, quality of life, and social goals. Such an approach appears to be much more promising than top-down technological fantasies as often provided by large companies in fields like housing, transport, the use of public space, or healthcare. The title refers to a question put to Stan Laurel by Oliver Hardy in countless movies. Here the latter stands for a city calling industry for help. The delivery as we know can lead straight to disaster, but in real life it is less funny than with the two great comedians.
\end{abstract}

Cities across the world face a number of pressing and long-term challenges, including massive urbanization with growth in size and density as well as the need to de-carbonize the whole urban metabolism. This includes transport, construction, and consumption as well as implementation of climate mitigation strategies. Further, and in many different ways, cities play an important role in key policy areas like social cohesion, education, housing, and health, with the aim to provide for an affordable and high quality of life. Finally, as most real politics is local, cities are pivotal for further developing democracy, sourcing the creative potential, fostering innovation, and increasing the political participation of their inhabitants.

In the last decades, digitalization has been entering through all kinds of doors, with great promises and massive power to transform traditional forms of evidencegathering, business models, governance structures, communication patterns, and decision-making. Ubiquitous optical and sensor systems and broadband networks provide for massive and reliable data which can be analyzed with powerful methods ranging from machine learning to complex systems analysis. In fields like health or

\footnotetext{
M. Stampfer $(\bowtie)$

Vienna Science and Technology Fund (WWTF), Vienna, Austria

e-mail: michael.stampfer@wwtf.at
} 
public transport, the power to collect, own, combine, and interpret data has become as important as the ownership of operating theaters or subway lines. Cities across Europe therefore speed up with digital policies and actions. Speed however is a relative term as many cities face huge obstacles with endless layers of bureaucracy, laws cementing the status quo, conflicting interests, and limited budgets.

Now we can close our eyes for a moment and think of a stressed-out, impatient Oliver Hardy turning to Stan Laurel, inconspicuously standing close by: "Why don't you do something to help me?" This is how many cities have acted: Most conveniently, industry also happens to wait already on the doorstep with beautifully rendered turnkey solutions or mobile apps to solve most wicked societal problems. Unfortunately, for miracles like thumb-as-lighter, finger-wiggling, and kneesyearsy-nosey, the transfer of skills to the unprepared mind has its consequences: We let our imagination still flow for a moment, to uphill piano transports, escalating cream pie fights, or the sweet dynamism of destroyed kitchen porcelain. At the end, we listen to a sobbing Stan Laurel pleading innocent and to the famous Oliver Hardy line: "That's another nice mess you've gotten me into." However, contrary to Stan, industry often does not end on the losers' side.

"Smart City" has become a key term for urban policies dealing with data-driven, often large-scale solutions to better manage urban agglomerations. For cities to enter the next steps of digitalization means facing a number of challenges; the following five points can be seen as examples:

A first one might be just termed "turnkey"-like supplying whole neighborhoods with readymade supply for de-centralized energy production and storage with smart grids and meters. This is a very good idea (seriously, and at the same time we hear Oliver Hardys' voice again), a big trend, and it helps transform the energy system, but it is also extremely tricky and in need of long and patient co-development between private and public actors.

A second challenge is "you may keep the hardware," as the tram network or bus fleet stays with the public utilities, but the data solutions managing the user interface are being serviced by private providers. That one might not be such a good idea, as data today defines strategies and directs revenue streams. Therefore, cities try to establish their own data management structures.

A third one can be termed "improved, electrified, without driver, no change of mind required" which is a nice combination of current user habits and future industry profits. Take as an example the effort to help cities get rid of the car pandemic ... by providing technically enhanced cars: As without drivers they for sure will after the trips miraculously disappear somewhere. A better idea might be to establish demandbased co-creation processes with citizens on how to redefine and regain urban space and broader mobility concepts.

A fourth challenge is the "law-overriding platform economy," successfully ignoring taxation, employment laws, or sector regulations, just because they can. When cities or regions hit back with their still powerful old-world instruments like taxi license ordnances, regulations for touristic accommodation, or labor standards, they might fend off the tech giants for a while, albeit at the price of stifling innovation and paying rents to incumbents. 
A fifth example is "give us your city and make us happy," with again tech giants collecting and sucking off all kinds of data without leaving sustainable profits for the city and its inhabitants. Many examples start with low capabilities of city actors to frame, organize, manage, and capitalize digital platforms and services, therefore handing over to industrial actors. They then provide street view, health diagnosis, or pan-optical surveillance, without telling what they do with the data collected and how they re-use and sell them.

Such examples hopefully show how important it is for cities to develop and implement an active political approach toward data and data policies. This starts with focusing on data protection and privacy issues as well as with building up in-house competencies, extending to the creation and nurturing of local networks and knowledge hubs, as well as cooperation with academia and civil society. Strategies are important, and more so are scores of individual projects, ranging from supported small citizens' initiatives to large-scale change efforts in health, transport, energy, or participation.

The bottom-up approach is specifically important: Cities have to become active and experiment, for three reasons: First, in many fields connected with large-scale data collection, the platform economies, and their digitally driven influencing strategies on our future behavior, we see national, European, or global regulation still at an infant stage, with large companies successfully battling legislative efforts. Second, for changes in the way cities work and resources are being used, the ideas and needs of citizens are often the best way to reclaim public space, data sovereignty, and carbon neutrality. Data sovereignty is of specific importance here, as city administrations are also hungry for data and should not misuse them. Third, living labs and trial and error are often much better-suited for lasting innovation than the top-down, turnkey solutions. As we of course also need general laws and regulations, such an approach can serve as a valuable learning space.

Digital Humanism plays a central role in shaping what cities do and how they do it, as a state of mind and as a guiding principle. City politics and administration do not have to re-invent the wheel as there are many successful examples in history how to create public goods in areas like housing or public transport. The "state of mind" issue appears to be of specific importance as the question is: Who shall prosper? How to include all —or at least most—inhabitants in decision-making and have them share the benefits? What is good life in cities in key elements like social interaction, health, resource consumption, or space to live?

These are not really new questions; take the example of a city like Vienna in pre-digital times: Powerful public infrastructures, a huge communal housing program, top-class health for all, and strong social networks have been the political priorities for more than 100 years. As one consequence, Vienna in the last decade could successfully take the next step and become one of the leading Smart Cities across the globe, combining goals and measures for social inclusion, for innovation, and for reduction in resource consumption and carbon emissions.

The next, ongoing step is to frame digitalization politically and in all policies to respond to the Digital Humanism number one question: How can we preserve and constructively transform the best of our current civilization into the digital world? 
We have to build laws, norms, structures, and knowledge bases to allow our key institutions to thrive also in the future: This is the representative democracy, the welfare state, the rule of law, and the social market economy. All of them can unfold even better in a strongly digitized world. However, leaving this transformation without strong political action, we invite big market actors to suck off our data, to not pay taxes, or to manipulate elections and our individual actions. Without such frameworks, we write an invitation letter to illiberal democracy and to the surveillance state, as unfortunately the libertarian equation of greater freedom through unregulated digital interactions has proved to be a two-edged sword at best.

Digital Humanism therefore means active politics and regulatory frameworks in addition to ethics, knowledge bases, and infrastructures. Cities can do a lot in all these respects:

- Active politics is about setting an agenda, finding majorities, and making issues visible through priority setting and sometimes loud, bold statements. Mayors and cities are more powerful than one might be aware of. They can mobilize an electorate and are in charge for big decisions in city development. A number of cities like Barcelona or Amsterdam have already implemented policies that certain data sets collected by big companies have to be made available to citizens, small companies, and initiatives. Cities can play an important role in guaranteeing individual and collective data sovereignty and help make data a resource for social and economic purposes on a local level. Cities can form coalitions and pressure groups, as with the Digital Services Act on the European level.

- As in former industrial revolutions, regulatory frameworks in many ways still wait to be developed. In the meantime, policy makers also on the city level have to respond by shifting the objective: As already stated, such regulations might not always be rooted in the digitization as such. Instead, we find them in good old labor laws, transport licenses, or accommodation rules. As a consequence, Uberstyle transport might come to an abrupt halt; and Airbnb hosts find unexpected obstacles. Such measures help stop the erosion of justified standards in labor relations or fair competition. They might at the same time also stifle competition, feed lazy incumbents, and prevent customer value from materializing. Therefore, we need new forms of regulation, and cities can be strong actors between a Charybdis called good old times and the Scylla of unregulated global platforms devouring scores of workers and businesses.

- On the basis of strong political and regulatory will, ethics issues come in through many doors. A first door is education, with new curricula to help the gap between the "lots of ethics but no idea about technology" approach in the more humanistic colleges and the "give us points to connect and gratifications and progress at all price" ideology of technical education. Such an integration should start early on, and regional authorities can play a role as they often run the more basic education. A next door is the purchasing power of cities asking for high ethical standards in all kinds of digital goods and services. A third one is supporting grassroot and civil society actors concerned with privacy, data sovereignty, or creative work; cities can subsidize and promote movements, festivals, neighborhood initiatives, 
and a score of other activities. One final point here goes in the same direction, supporting a critical discourse, where the ethics part is about taking the side of the less fortunate part of the population by countering a narrative like: "we all have to be techno-optimists" by stating that without caring mainly the strong and powerful will collect the benefits when this narrative materializes.

- Knowledge bases-besides schools-include strong universities and research providers. Many cities employ active policies to support their local research base. Cities like Berlin have created cross-disciplinary centers, while in Vienna we find a research funding program called Digital Humanism to link Computer Sciences with Social Sciences and the Humanities. Here the idea is to collaboratively create theories, methods, approaches, and practices as well as to find a common understanding of new technological and social phenomena. Such initiatives shall help to wake up the soft sciences for the challenge of the digital revolution, while it shall provide the engineers with a framework of how a good, inclusive society shall further unfold with the help of their models and artifacts. One guidepost for such activities is the Vienna Manifesto for Digital Humanism that has been co-developed by local and international researchers of various backgrounds with support from Vienna policy makers.

- Infrastructures is another broad topic where cities can play an important role: First by helping to provide top-class broadband networks, second by strongly supporting their own departments and utilities as well as across private industries to come forward with up-to-date solutions, both technically and non-technically. Third, and perhaps most important, is the ability of the public sector to effectively deal with their data. Currently public actors collect loads of data but often without proper policies and practices how to best store, validate, connect, and share them. Within the framework of the recent European data protection regulations, there are many ways to better steer policy, deliver results, and allow research to access data. Unfortunately, many public actors including cities currently face a dilemma: As they cannot always effectively transform traditionally high standards of service into the digital sphere, they have to give carte blanche to all kinds of companies including the global platform firms by letting them collect, analyze, and capitalize the data. Examples from the health and public transport sector show that such an approach can be dangerous: Public actors should at least have the competence to govern public domain data, being able to decide what shall remain in the public domain and what can be handed over to the private sector.

As we see, Digital Humanism is a mindset and a tool for cities, a mindset in emergence and a tool in the making. We all can be part of this process. Why don't you do something to help us? for now is a serious question. 


\section{Further Reading}

Bria, F., https://www.youtube.com/watch?v=9i2dZgbsagY. (Francesca Bria talking about what has been going on in Barcelona and other cities regarding data sovereignty and giving back data value to the people)

City of Vienna, https://smartcity.wien.gv.at/en/approach/framework-strategy/ (The Vienna Smart City strategy and approach can be found here)

Digital Humanism Initiative Vienna, https://dighum.ec.tuwien.ac.at/dighum-manifesto/ (This is the Vienna Manifesto on Digital Humanism)

Hal Roach Productions, https://www.youtube.com/watch?v=DiFEFL6ThRI (Stan Laurel showing Oliver Hardy kneesy-earsy-nosey, from the movie Fra Diavolo)

Vienna Science and Technology Fund (WWTF), https://www.wwtf.at/digital_humanism/index. php?lang $=$ EN (WWTF funding activities)

Weizenbaum Institute, https://www.weizenbaum-institut.de/en/ (Weizenbaum Institute in Berlin presents itself)

Weizenbaum Institute, https://www.youtube.com/watch?v=B9_EeHjNcVE (video with presentations of the research groups)

Zuboff, S., https://www.youtube.com/watch?v=fJ0josfRzp4 (A long lecture by Shoshana Zuboff on Surveillance Capitalism)

Open Access This chapter is licensed under the terms of the Creative Commons Attribution 4.0 International License (http://creativecommons.org/licenses/by/4.0/), which permits use, sharing, adaptation, distribution and reproduction in any medium or format, as long as you give appropriate credit to the original author(s) and the source, provide a link to the Creative Commons license and indicate if changes were made.

The images or other third party material in this chapter are included in the chapter's Creative Commons license, unless indicated otherwise in a credit line to the material. If material is not included in the chapter's Creative Commons license and your intended use is not permitted by statutory regulation or exceeds the permitted use, you will need to obtain permission directly from the copyright holder.

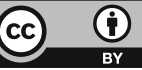

